\title{
Failure to account for behavioral variability overestimates bonobo populations and compromises accuracy in population monitoring
}

\author{
Erin G. Wessling ${ }^{* 1, \varpi}$ and Martin Surbeck ${ }^{1}$ \\ ${ }^{1}$ Department of Human Evolutionary Biology, Harvard University, Cambridge, USA
}

\begin{abstract}
Wildlife population monitoring depends on accurate counts of individual animals or artefacts of behavior (e.g., nests or dung). In indirect surveying, which depends largely upon artefacts of behavior, likelihood to encounter indirect signs of a species is derived from both artefact production and decay, although variability in behaviors relevant to artefact abundance is rarely considered in population estimation. Here we demonstrate how ignoring behavioral variability contributes to overestimation of population size of an endangered ape endemic to the Democratic Republic of the Congo, the bonobo (Pan paniscus). Commonly, a single metric of sign production (i.e., nest construction) is used to estimate bonobo density, assumed to be representative of bonobo nest behavior across all contexts. We estimated nest construction rates from three bonobo groups within the Kokolopori Bonobo Reserve and found that nest construction rates in bonobos to be highly variable across populations as well as seasonal within populations. Failure to account for behavioral variability in nest construction leads to potentially severe degradation in accuracy of bonobo population estimates of abundance, accounting for a likely overestimation of bonobo numbers by $34 \%$, and in the worst cases as high as $80 \%$ overestimation. Using bonobo nesting as an example, we demonstrate that failure to account for inter- and intra-population behavioral variation compromises our ability to monitor population change or reliably compare contributors to population decline or persistence. We argue that variation in sign production is but one of several potential ways that behavioral variability can affect conservation monitoring, should be measured across contexts whenever possible, and must be considered in population estimation confidence intervals. With increasing attention to behavioral variability as a potential tool for conservation, conservationists must also account for the impact that behavioral variability across time, space, individuals, and populations can play upon precision and accuracy of wildlife population estimation.
\end{abstract}

nests | survey | seasonality | group level | behavioral variation Correspondence: ewessling@fas.harvard.edu

\section{INTRODUCTION}

Wildlife monitoring and assessments of population size are crucial components of biodiversity conservation. To effectively monitor species, the information gathered must be an accurate reflection of true status of a population while free of bias and precise enough to allow for differences in status to be informative (Kremen et al. 1994). Wildlife monitoring involves the quantification of direct or indirect observations of animals, which, in lieu of cost-prohibitive censusing, are commonly performed as surveying of subsets of the areas of interest. Sampling by direct observation have traditionally meant quantification of observations of animals by a surveyor (Buckland et al., 2001; Kühl, 2008), although technological and analytical improvements increasingly permit the use of remote methods to estimate animal abundances based on observations during camera trap or acoustic surveying (e.g., (Campos-Candela et al., 2018; Cappelle et al., 2019; Crunchant et al., 2020; Howe et al., 2017; Moeller et al., 2018; Nakashima et al., 2018).

For especially elusive species or for surveying in dense vegetation, however, conservationists typically rely on surveying of indirect signs of animal presence (Buckland et al., 2001; Plumptre, 2000). Examples of indirect signs can range from dung (e.g., (Barnes, 2001; Nchanji Plumptre, 2001; Plumptre, 2000), to remnants of behavior (e.g., nests of great apes; (Kühl, 2008). As in direct surveying, a great amount of attention centers around designing surveys to ensure sampling effort is sufficient and that animal counts are robust (Buckland et al., 2001). However, unlike direct surveying, the use of indirect surveying also necessitates accounting for auxiliary variables that account for potential sign abundance, such as rates of sign production and decay (Buckland et al., 2015). While the use of indirect surveying facilitates the possibilities for surveying wildlife populations, the additional consideration of sign detectability represents a significant potential source of error. Some authors argue that this component of population estimation requires greater amounts of attention, as this is where potential biases are most easily introduced (Strindberg et al., 2018).

For example, conditions of the local environment are a commonly acknowledged influence on probability of sign encounter, and heterogeneity is common in metrics of sign decay rates across locations (e.g., (Bessone et al., 2021; Kuehl et al., 2007; Walsh White, 2005). In both dung and nestcount surveying, sign decay is affected by climatic seasonality, especially in rainfall, as well as other contextual factors such as construction material or dung matrix, storm frequency, and sun exposure (Bessone et al., 2021; Kamgang et al., 2020; Kouakou et al., 2009; Laing et al., 2003; Morgan 
et al., 2016; Nchanji Plumptre, 2001; Plumptre, 2000). Because of these environmental influences, it is commonly recommended that local measures of decay rates must accompany surveying, as failure to do so may result in imprecise measurement and hinder validity of inter-site comparisons (e.g., (Bessone et al., 2021; Kühl, 2008; Laing et al., 2003; Mohneke Fruth, 2008).

However, an often-overlooked component of density estimation relates to the variation in production of indirect signs, which is a derivative of behavior by the species surveyed (although see (Todd et al., 2008) and central to density estimation in indirect surveying. Rates of production behavior for many indirect signs are typically treated as static entities - derived from a single group (e.g., (Hedges et al., 2005; Kouakou et al., 2009; Morgan et al., 2006; Plumptre Reynolds, 1997; Todd et al., 2008), or even a single individual (Viquerat et al., 2012) — and considered representative for the whole species. Single measures are likely common because measurement of production behavior must be directly observed to be quantifiable, which negates the need for indirect surveying as population size is then already known.

Nevertheless, given we know that behavior is variable within a species it may be problematic to rely on a single measure to represent species-level patterns. Variation in animal behavior may be influenced by the environment (e.g., (Kalan et al., 2020) but can also vary without clear environmental drivers (e.g., (Luncz et al., 2012; Samuni et al., 2020). Therefore, the influence of environmental factors in sign production rates remains relatively unevaluated (although see (Todd et al., 2008). With behavioral variation becoming increasingly relevant to issues of conservation policy (Brakes et al., 2021; Carvalho et al., in press), we may wish to ask if it might be an overlooked consideration in monitoring as well? If so, behavioral variability is likely to impact our ability to accurately monitor and assess impacts of wildlife populations.

If we wish to investigate the role of behavioral variation to species monitoring, then highly behaviorally flexible clades like great apes are ideal models. Apes are among the most extensively documented clades to exhibit behavioral variation and likely also among the most flexible (e.g., (Kalan et al., 2020). As ape surveying is conducted predominately via indirect surveying, evaluating sign production variability in a species like the bonobo (Pan paniscus) represents a straightforward approach to addressing such concerns. Indeed, in the case of ape nests, construction is known to vary according to weather patterns (Stewart et al., 2018), therefore it is already likely that we have ignored potential behavioral variation which affect ape density estimations. Bonobos are endemic only to the left bank of the Congo River in the Democratic Republic of the Congo (DRC), and as one of the ape species under greatest threat, accurate population monitoring is most critical (Fruth et al., 2016). There are only an estimated minimum of 15-20,000 remaining individuals in the wild (IUCN ICCN, 2012), making bonobos among the least numerous of the ape species. Under-surveying of bonobo populations has led to an inability to reclassify the species as critically endangered (Fruth et al., 2016).

Bonobos, like all apes, make nests in which to sleep in at night (Fruth Hohmann, 1993), which is the predominant target of observation in bonobo surveys (Kühl, 2008). Bonobos regularly also construct nests for lounging during the day (Fruth Hohmann, 1993), thereby providing ample opportunity for construction behavior to vary. While nest decay rates for bonobos have been measured at few sites (Appendix S1), nest construction rate has to date only been measured in a single location (LuiKotale: (Mohneke Fruth, 2008). Furthermore, a portion of bonobo densities have also been estimated under the assumption of a single nest constructed per day (e.g., (Hashimoto Furuichi, 2002; Reinartz et al., 2006; Van Krunkelsven, 2001). Meanwhile in chimpanzees, the sister species of bonobos, nest construction rate vary by ca. 5\% (Kouakou et al., 2009; Appendix S1). Generally, bonobos are argued to be comparatively less variable in their behavior than chimpanzees (Hohmann Fruth, 2003) and occupy considerably smaller and less environmentally variable biogeographic range (Fruth et al., 2016). Therefore, it may be expected that behavioral variation in nest construction is comparatively lower in bonobos than chimpanzees. However, even as a member of a behaviorally flexible clade, do bonobos demonstrate cross-site variation in nest construction rates, and what impact might this behavioral variation have on our ability to accurately monitor bonobo populations?

\section{METHODS}

To evaluate potential biases that contribute to nest construction rates in bonobos, we collected data on the nesting behavior of three distinct social groups at the Kokolopori Bonobo Reserve in the Democratic Republic of the Congo (Surbeck et al., 2017). We collected data during 410 full-day focal follows (Altmann, 1974) over the course of one calendar year (September 2020 - August 2021) on a total of 33 adult individuals (10 male, 23 female; mean days/individual:12.4 days, range: 3-25) from the three neighboring communities (Ekalakala, Kokoalongo, and Fekako) with a mean of 137 focal days per group (range: $77-172$ ). During focal follows, observers marked each instance of nest construction and the species used to construct the nest. As focal follows were sometimes interrupted or focal animals were lost over the course of the day, we restricted all subsequent analyses to focal follows at least 6 hours in length that spanned the entirety of daylight hours (from morning nest to night nest) to reduce the likelihood that observations of nest construction were missed. The restriction of data which meet these criteria therefore reduced the dataset from 410 to 386 follow days.

Few researchers have previously argued that day nests are of flimsier construction than night nests and therefore should not be considered in calculations of nest construction rates (Fruth Hohmann, 1993; Van Krunkelsven, 2001), however most authors have nonetheless included day nests in their calculations of nest construction rate (Kouakou et al., 2009; Mohneke Fruth, 2008; Morgan et al., 2006; Plumptre Reynolds, 1997). Regardless of structural robustness at construction, because day nests still require the bend- 
ing of branches in a manner that is indistinguishable from a night nest during surveying, they must be included in nest construction rate, as robustness of nest construction only relates to the durability (i.e., rate of decay) of the nest but not its identifiability. In this sense, future studies should measure if day nest durability differs from that of night nests.

To calculate average nest construction rate at Kokolopori, we fitted a Generalized Linear Mixed Model (GLMM; Baayen, 2008) with Poisson error structure, with the number of nests constructed during the course of a follow as the response. We included the sine and cosine of the radian of Julian date of the focal follow to test for a potential seasonal effect (Stolwijk et al., 1999) in nest construction behavior, as well as the test predictor of sex. We accounted for potential influence of group as a control predictor and included individual and date as random effects. Lastly, to account for the variable effect of observational effort (i.e., duration) we included an offset term of the log of duration of focal observation.

We found no issues with model overdispersion (dispersion parameter $=0.42$ ) collinearity among predictors, or model stability. To evaluate model significance, we compared the fit of the model to a null model lacking the test predictors of sex and seasonal terms (but otherwise identical) using a likelihood ratio test (Dobson Barnett, 2018). We evaluated predictor significance similarly, by excluding each predictor and comparing each reduced model to the full model using a likelihood ration test (ibid.). We assessed model stability by excluding each level of the random effects one at a time and comparing the estimates with those derived for the full data set. Lastly, we derived confidence intervals by means of parametric bootstraps (function bootMer of the package 'lme4'; Bates et al., 2015). We used the intercept of the model to derive an average nest construction rate for the population, while correcting for all significant predictors, if relevant. For comparability, we also calculated average nest construction rate using Mohneke Fruth's (2008) calculation, using party composition from group follows for the same period, using 293 days and 10635 30-min party composition scans.

If nesting behavior varies seasonally, surveying performed during one period of an annual cycle may identify a greater number of nests than during another period of the year despite no change in the number of nest constructors. Further, the time it takes for a nest to decay will affect the interval during which construction behavior is relevant to a survey. In this sense, the time it takes for a sign to decay represents also the time window within which sign production behavior is relevant to that survey. If production behavior is temporally variable, then both decay rate and survey date dictate the time window over which construction behavior is relevant to a given survey. In order to get a better understanding of the seasonal variability in average nest construction behavior ultimately relevant for bonobo population monitoring, we used each of the four nest decay rates previously published for bonobos (Appendix S2) as a sampling window prior to each potential survey day during the year. Because we do not have multiple years of data, we treated date cyclically when sampling, e.g., using a 183-day decay rate the nest construction rate estimated on January 1 includes focal follows on the last 183 days of the calendar year). Then, we calculated the average nest construction rate for each combination of decay rate and date in the year.

Lastly, to contextualize the impact of variable nest construction rates on estimates of bonobo densities across their range, we considered the variability of published nest decay rates and nest construction rates for bonobos (Appendix S1, S2) for their impact to published bonobo density estimations. Commonly, ape density estimates are derived using the following generalized equation: $D=N /(A \times p \times r \times t)$, where $N$ is the count of nests discovered, $A$ is the area surveyed, $p$ is the proportion of nest builders within the population, $r$ is the nest production rate, and $t$ is the nest decay rate (Buckland et al., 2001; Kühl, 2008). We replaced original nest production and decay rates with all combinations of these values (including rates from Kokolopori derived here) and permuted all possible outcomes of density for each published non-zero density estimate. We additionally considered the effect of seasonal variation on nest construction rate in these permutations by allowing for density estimations to derive from a balanced dataset of either published values from LuiKotale (Mohneke Fruth, 2008) or any of the possible construction rate values (i.e., seasonally varying construction rates) from our Kokolopori dataset, based on the decay rate of 76 days (Mohneke Fruth, 2008).

\section{RESULTS}

Our test predictors (seasonality, group, and sex) significantly contributed to explaining variation in nest construction rate (full-null model comparison: $\chi^{2}=26.28, \mathrm{df}=3, \mathrm{p}<0.001$ ). Specifically, nest construction at Kokolopori is a seasonal behavior, with highest rates of nest construction during October (the wettest month of the year: Samuni et al., 2020) and lowest number of nests produced during April $\left(\chi^{2}=24.31\right.$, df $=2, \mathrm{p}<0.001)$. We did not find group or sex differences in nest construction rates (Table 1). As rainfall is a common predictor of variability in nest decay and nest construction type (Stewart et al., 2018), we also fitted an ad hoc model identical to our Poisson model, but replacing the generic seasonal term with cumulative rainfall in the 4-weeks prior to each focal. We found that rainfall significantly predicted variation in nest construction rate (full-null model comparison: $\chi^{2}=$ 5.179 , df $=1, \mathrm{p}=0.023$; Appendix S3), with bonobos constructing more nests during periods of high rainfall. This pattern corresponded to a difference of 0.65 nests/day (range: $1.54-2.19$ nests/day) over the range of monthly rainfall patterns at the site (range: $7-221 \mathrm{~mm}$ cumulative rainfall).

When considering average observation duration (9.85 hours), average nest construction at Kokolopori was $1.92 \pm$ 0.06 nests per day (SE; model intercept, back-transformed), considerably higher than the previously published estimate from LuiKotale (1.37 nests/day: Mohneke Fruth, 2008), as well as from the commonly assumed rate of 1 nest/day (Hashimoto Furuichi, 2002; Inogwabini et al., 2008; 

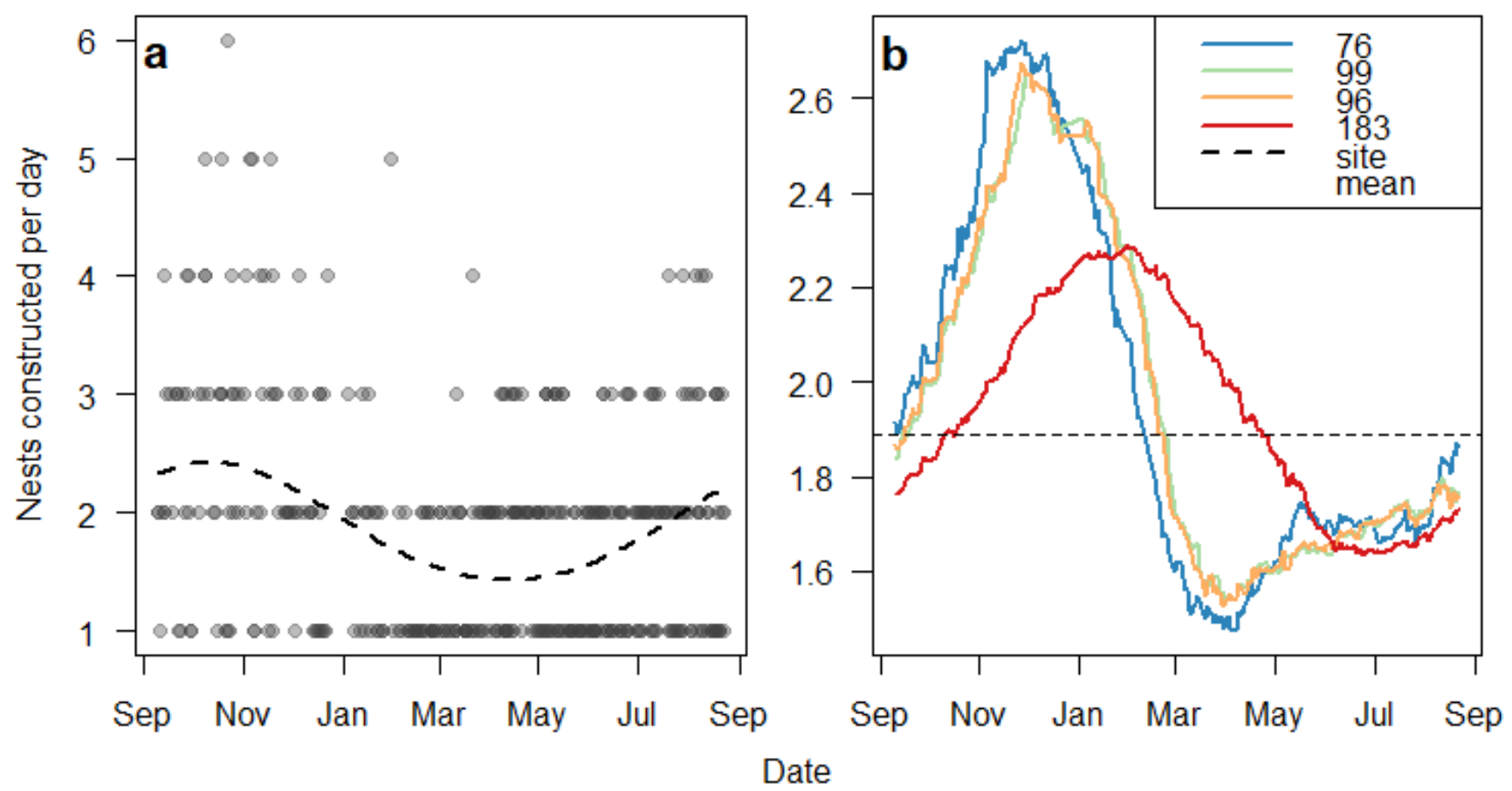

Figure 1. (a) Seasonal variation of nest construction behavior in two communities at Kokolopori Bonobo reserve, circles represent the number of nests constructed per focal follow and the dashed line represents the model line. (b) Average Kokolopori nest construction rates across four sampling windows (color coded according to common nest decay rates [in days]).

Reinartz et al., 2006; Van Krunkelsven, 2001). When calculated following Mohneke Fruth's (2008) method which presumes sex differences in construction behavior and estimates an average construction rate based on average party sex ratios, we found that nest construction rate (1.92 nests per day) did not differ from the rate derived from the GLMM.

Across the four nest decay sampling windows used, intra-annual variation in construction rate at Kokolopori averaged 1.04 nests/day (range: $0.66-1.24$ nest/day variation per decay rate), although average construction rate over the year varied minimally across different nest decay rates used $(0.003$ maximum difference between averages). All estimated construction rates at Kokolopori averaged higher than the previously published construction rate from LuiKotale (Mohneke Fruth, 2008; Figure 2).

Permuted bonobo densities across construction rates always predicted overestimation in original values (Table 2). Across our dataset, overestimation of bonobo densities averaged $33 \pm 5 \%$ (SD) when permuted across all construction rates, reaching up to $80 \%$ overestimation. Accounting for intra-annual variation in nest construction rates in our permutations reduced overestimation rates minimally ( $1 \%)$ but increased potential severity of density overestimation by up to $15 \%$. When permuting densities across construction rates only, the five highest bonobo densities (Figure 3) suffered the highest rates of overestimation (mean \pm SD: $36.5 \pm$ $11 \%$, range: $27-63 \%$ ). Original densities were only underestimated (\% change) in cases where nest decay rates were permuted at shorter decay rate than was used in the original study, specifically the density estimates from Serckx et al. (2014) which used the maximum decay rate of 183 days
(Figure 3). Overestimation and underestimation percentages became more severe when variation in both nest construction and decay were permitted, underlining that uncertainty in both estimates enhances misestimation regardless of direction.

Table 1. Effect of season (represented by sine and cosine of Julian date) and sex on nest construction behavior at Kokolopori Bonobo Reserve ( $\mathrm{n}$ $=268$ ).

\begin{tabular}{|ccccc|}
\hline Predictor & Estimate \pm SE & $\mathrm{Cl}_{(95 \%)}$ & $X^{2}$ & p-value \\
\hline Intercept & $-1.63 \pm 0.06$ & $-1.761,-1.525$ & - & - \\
Sine & $-0.26 \pm 0.05$ & $-0.368,-0.147$ & -4.869 & $<0.001$ \\
Cosine & $0.05 \pm 0.05$ & $-0.063,0.154$ & & \\
Group (Fekako) & $0.13 \pm 0.11$ & $-0.081,0.328$ & & \\
Group & $0.04 \pm 0.08$ & $-0.115,0.199$ & 1.494 & 0.473 \\
(Kokoalongo) $^{\mathrm{a}}$ & $-0.11 \pm 0.08$ & $-0.276,0.053$ & 1.670 & 0.196 \\
Sex (Male) & & & \\
${ }^{\mathrm{a}}$ Reference category: Ekalakala; ${ }^{\mathrm{b}}$ Reference category: Female & &
\end{tabular}


bioRxiv preprint doi: https://doi.org/10.1101/2021.12.22.473935; this version posted December 24,2021 . The copyright holder for this preprint (which was not certified by peer review) is the author/funder. All rights reserved. No reuse allowed without permission.

Table 2. Average changes in density estimations from original reported values based on permutations of all potential nest decay and/or nest construction rates, calculated either using site-wide averages or allowing for seasonal variation.

\begin{tabular}{|lcccc|}
\hline Permutation type & $\begin{array}{c}\text { [Overestimate] } \\
\text { Mean } \pm \text { SE (\%) }\end{array}$ & $\begin{array}{c}\text { [Underestimate] } \\
\text { Mean } \pm \text { SE (\%) }\end{array}$ & $\begin{array}{c}\text { SD } \\
\text { (\%) }\end{array}$ & $\begin{array}{c}\text { Range min, max } \\
\text { (\%) }\end{array}$ \\
\hline $\begin{array}{l}\text { Decay and construction (site } \\
\text { average) }\end{array}$ & $-38.2 \pm 1.5$ & $55.8 \pm 9.4$ & 38.3 & $-71.7,140.8$ \\
$\begin{array}{l}\text { Decay and construction (with } \\
\text { seasonality) }\end{array}$ & $-37.1 \pm 0.1$ & $60.0 \pm 0.6$ & 39.3 & $-80.1,140.8$ \\
Construction only (site average) & $-29.1 \pm 2.8$ & - & 16.4 & $-47.6,0.0$ \\
Construction only (with seasonality) & $-28.2 \pm 0.2$ & - & 17.4 & $-63.3,0.0$ \\
Decay only & $-33.5 \pm 3.1$ & $35.0 \pm 4.4$ & 40.6 & $-58.5,140.8$ \\
\hline
\end{tabular}

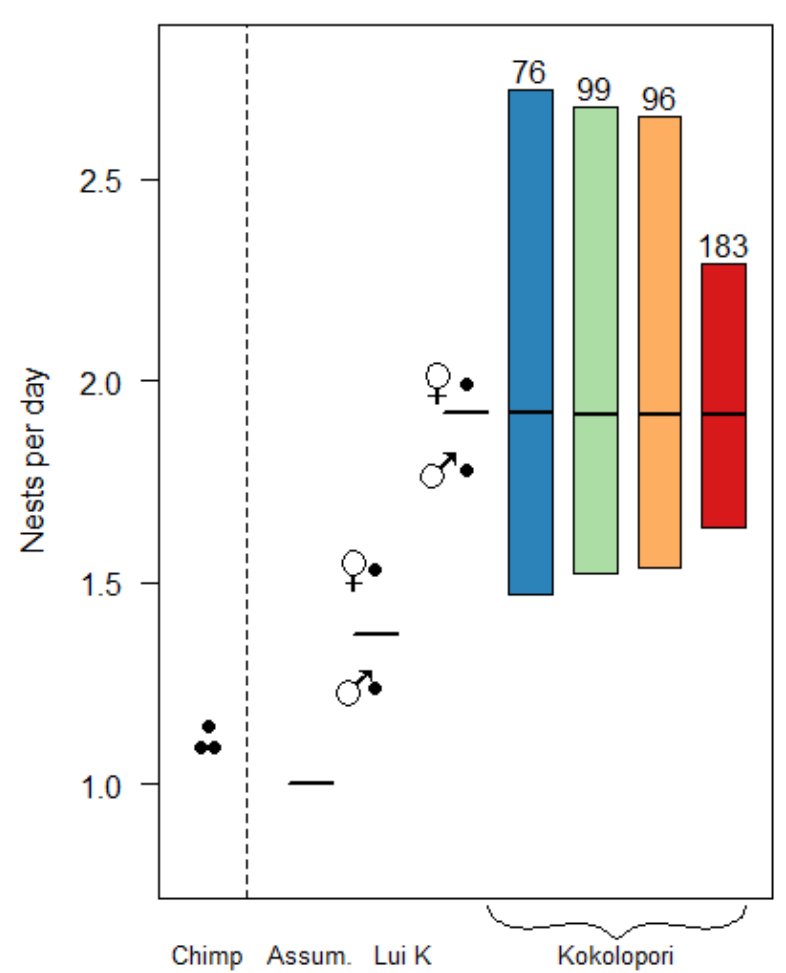

Figure 2. Nest construction rates from chimpanzees ('Chimp', left dots; Kouakou et al. 2009, Morgan et al. 2007, Plumptre Reynolds 1997) and bonobos. Bonobo construction rates include the common assumption of 1 night nest/day ('Assum.', left bar), calculated rates from LuiKotale males, females, and average ('Lui K', dots and bar; Mohneke Fruth 2008), construction rate from Kokolopori using Mohneke Fruth's (2008) calculation (dots and bar), as well as Kokolopori nest construction rates based on seasonal sampling using four nest decay windows (colored boxes, labeled by days to decay).

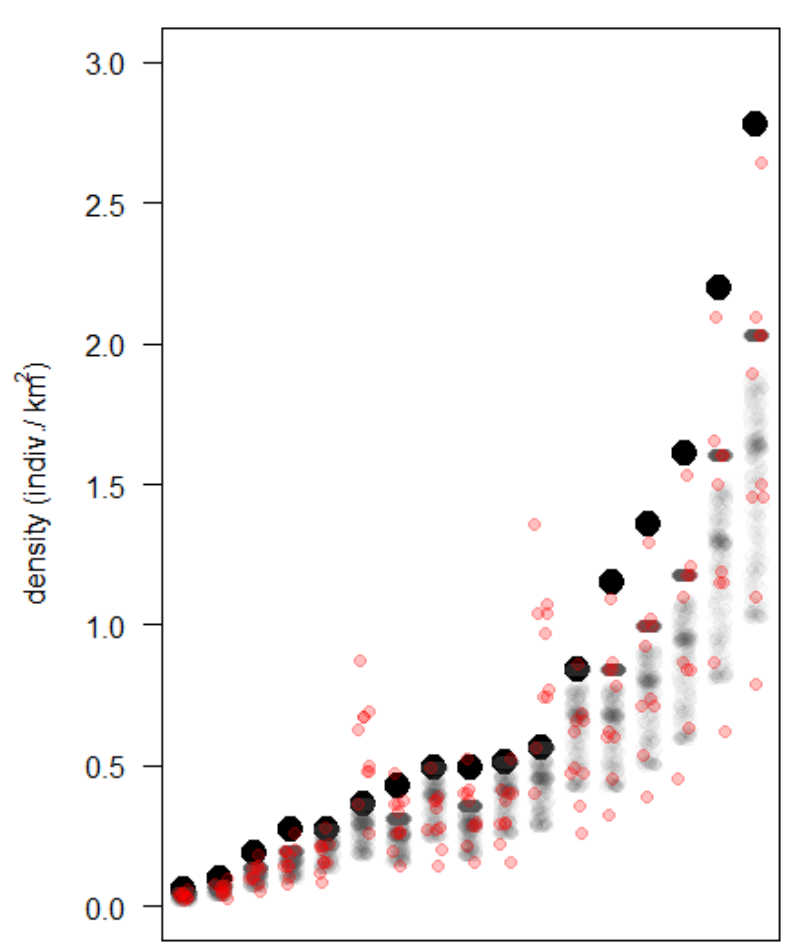

Figure 3. Bonobo density estimations (larger black dots, ordered low to high) and density values permuted from all observed bonobo nest construction rates (grey dots; including seasonal variation at Kokolopori) or observed nest construction rates and nest decay rates (red dots; sitebased average values only). 


\section{DISCUSSION}

When counts of animal populations depend on artefacts of behavior, wildlife monitoring methods must consider variability in animal behavior to estimate populations accurately. Our analysis demonstrates that behaviors relevant to monitoring great ape populations can be considerably variable and significantly impact population assessment. We demonstrate that bonobos not only differ between populations in the number of nests that they construct, but also that within a single population this behavior is highly variable. As a result, it is likely that we have overestimated the number of bonobos remaining in the wild by an average of $34 \%$, with worst case scenarios leading to an overestimation by up to $80 \%$.

Much of this overestimation derives from the reliance upon a single measure of production behavior being used for bonobo population density estimates. We present here a second measure of nest construction rate and evaluate its seasonal variability. Given that the construction rate at Kokolopori is considerably higher than the single previously published estimate and that the Kokolopori site does not represent any overt environmental or behavioral outlier, it is likely that we have historically overestimated bonobo abundance. While methodological comparison with camera trap studies suggests that nest counts may commonly underestimate ape densities (7.5\%: Cappelle et al., 2019) the severity of potential overestimation by failure to account for behavioral variability in nest production still outpaces potential methodological underestimation from using nests as indirect signs during surveying.

The likelihood for over-estimation of bonobo populations becomes clearest when we consider the following scenarios. First, as all directly observed calculations of bonobo nest construction rates are greater than an assumed value of 1 nest/day, then estimates of populations using this assumed value are certainly overestimated. We found that published bonobo densities which relied on the assumption of one nest constructed per day were not only among the highest estimates, they also were the most likely to be severely overestimated. Second, given the Kokolopori nest construction rate is higher than the only other published rate (Mohneke Fruth, 2008), it is parsimonious to assume that bonobo nest construction rates at other, non-measured sites likely fall closer to one of the two measured estimates than to the assumed single nest constructed per day.

Consequences of ignoring behavioral variation. Our demonstration of the considerable inter- and intra-population variability in nest construction behavior has consequences for the ways in which we use population estimates. Specifically, cross-population differences in construction rates considerably hampers our ability to reliably compare inter-site differences in densities, or any subsequent inference upon differences in density therewithin. Several authors have argued for the necessity of measuring nest decay rates locally for each survey due to environmental influence on decay (e.g., Bessone et al., 2021; Mohneke Fruth, 2008; Plumptre Cox, 2006), however our results indicate that variability in nest construction behavior must likewise be considered. Without accounting for behavioral variation, our ability to discern drivers of variation in densities across populations remains obscured, which may consequently misinform conservation action.

Our results highlight further potential sources of biases for comparison of population estimates. We did not detect sex differences in nest construction rates at Kokolopori, whereas this was a clear (albeit statistically untested) pattern at LuiKotale (Mohneke Fruth, 2008). Sex biases in nesting behavior which are also variable across populations further complicate our ability to account for these biases in population estimation, especially across populations with varying sex ratios (Plumptre Cox, 2006). Populations may also differ in the durability of their day nests and their visual differentiation from night nests. While some surveyors claim to ignore day nests during surveying because they may be smaller or less robust in construction (e.g., Fruth Hohmann, 1993; Hashimoto Furuichi, 2002), the day nests at Kokolopori can appear largely indistinguishable from day to night (Appendix S4; Wessling unpubl. data). Consequently, it is likely difficult to reliably differentiate day from night nests during surveying in a manner that is objective across populations. Therefore, further information about the durability and distinguishability of day nests for surveying should be considered.

Further, seasonality in artefact production behavior has potential impacts on comparisons of population estimates across both time and space. First, monitoring of population change relies on repeated surveying of the same population, which rests upon the assumption that variation in the observation of behavioral artifacts solely reflects variation in animal densities. However, this assumption is violated if artefact production varies within a site. Consequently, it is necessary to understand the effect of within-population variability in relevant behaviors (e.g., nesting seasonality) on the robustness of trends derived from population resampling. A second consequence of behavioral seasonality is also that if it is commonplace across populations, that cross-site comparisons of bonobo densities may be simple artefacts of differences in surveying timing. That we find seasonality in artefact production behavior (nests: this study, defecation: Todd et al. 2008) as well as decay rates (e.g., nests: (Barnes, 2001; Bessone et al., 2021; Kuehl et al., 2007; Nchanji Plumptre, 2001) implies that conservationists must not only account for cross-site environmental differences, but also consider potential intra-annual environmental variation during survey planning and analysis.

Collectively, by failing to account for variation in nesting behavior we observe both clear overall biases (i.e., overestimation) in bonobo assessments, as well as uncertainty in estimation and comparison of individual populations. These effects have devastating consequences for bonobo conservation - a species for which severely data deficiencies hamper adequate conservation evaluation and prioritization (IUCN ICCN, 2012). The demanding logistics of surveying in extremely remote region of the Congo Basin necessitate ac- 
curate and comparative surveying because the resulting datapoints serve as the basis for understanding environmental correlates of density, which then are extrapolated to predict species densities across their range (e.g., Hickey et al., 2013; Nackoney Williams, 2013). If behavioral variation in nesting imparts unaccounted for variation in these densities, we may not only be inaccurately estimating the size of remaining populations, but also inaccurately evaluating predictors of population persistence or decline.

Surprisingly, we found that bonobo nest construction rates varied considerably more than chimpanzee construction rates. Bonobos demonstrate muted behavioral diversity relative to chimpanzees (Hohmann Fruth, 2003), a species well documented to exhibit a great amount of behavioral variation across its range (Kalan et al., 2020). Despite comparatively minimal ecological variation across the bonobo range (Furuichi, 2009), it is also notable that nest decay rates in bonobos extend across the majority of observed variation in chimpanzee nest decay rates. Therefore, a species like the bonobo can still demonstrate substantial behavioral variability which then impacts its monitoring, and that remnants of behavior can be just as variable (e.g., decay rates) or more variable (e.g., construction rates) than in a species like the chimpanzee which is known for behavioral flexibility (Kalan et al., 2020). Our results therefore underline that variability in behaviors relevant to monitoring may not necessarily follow general patterns of behavioral variability across taxa.

\section{How to address behavioral variability in population} monitoring. While the consequences of behavioral variation on population estimation may be extreme in this example, these results should caution conservation practitioners whose methods to quantify wildlife populations may be impacted directly by wildlife behavior (e.g., temporal patterns of camera trap triggering, trappability) or relics of behavior (e.g., dung counts). For example, timing of activity (e.g., diurnal, cathemeral) vary by local conditions and animals can be variably cryptic depending on environmental context (e.g., Oberosler et al., 2017; Rowcliffe et al., 2014). Collectively, these patterns point to the necessity of accounting for behavior in conservation monitoring.

But how can this reasonably be accomplished? It may be tempting to argue for direct sampling of behavior at each survey locality. However, the ability to directly observe wildlife behavior in a manner in which rates could be calculated negates the necessity of abundance sampling. Unlike artefact decay rates which can be observed without needing to directly observe individual animals, collecting information on artefact production behavior does necessitate direct observation. which may only be possible in few locations. Therefore, we could consider including variance introduced by inter- and intra-site variation within the confidence intervals of computed values. However, this may not be a realistic solution, as allowing for variance of potential nest construction rates introduced $60 \%$ variance in density estimates across our sample. Expanding the confidence intervals to include this variation would render cross-sample comparison functionally meaningless, an issue that no increase in the amount of survey effort could allow researchers to evade (Buckland et al., 2001).

Instead, a promising way forward may be to understand predictors of behavioral variation, such as environmental drivers like rainfall, which could be used as a proxy of artefact production behavior where behavioral sampling is not possible. To accomplish this, researchers who depend on metrics of behavior in surveying should aim to increase sampling efforts of that behavior across populations where behavior can be observed, and within those populations across time periods and seasons, to characterize behavioral variation for that species. Only then, once behavioral variability can be reliably tied to predictors for a species and then modeled across time and space, could this variability be included in subsequent interpretation of inter-survey variance. Because indirect monitoring of a given species therefore must depend on estimates acquired through direct behavioral observation, long term animal research sites must continue to be viewed as crucial components of species conservation (Campbell et al., 2011).

\section{Behavioral variation broadly impacts population mon-} itoring. The necessity for accounting for behavioral heterogeneity across individuals has received increasing attention in the conservation literature (Kelleher et al., 2018; Merrick Koprowski, 2017). Behavioral variability can considerably impact conservation effectiveness in a number of ways, from understanding its impact upon individual fitness to how it affects the suitability of conservation action across contexts and populations. However, the relevance of behavioral variability has rarely been discussed in the context of conservation monitoring, with two notable exceptions. First, behavioral variation in the form of movement as a behavioral trait creates considerable opportunity for biases in detectability (e.g., Hammond et al., 2021), but can also increase the variance and/or accuracy of population estimates, or the fidelity of connecting animal abundances to their potential drivers (e.g., Osipova et al., 2019; Rosenblatt et al., 2013). For ape monitoring, for example, these issues can occur if individuals or groups show spatiotemporal variation in territory use (e.g., Pruetz Bertolani, 2009), variable tolerance to territory overlap (e.g., Lucchesi et al., 2020), or even inter- or intra- population variation in distribution of where behavioral artefacts are deposited (e.g., nests: Hernandez-Aguilar Reitan, 2020). These patterns therefore contribute to variable stochasticity, clustering, or spatiotemporal distribution of behavioral artefacts which consequently impacts monitoring accuracy and inter-estimate stability (Buckland et al., 2001). For example, if an ape population sleeps next to their food resources, and resources vary within the year between clumped and evenlyspaced distributions, so too would their nests. However, variation in the distribution of nests over time would also be expected to affect patterns of detectability and appropriate surveying design.

Second, individual variability in boldness, neophobia, or other behavioral patterns (e.g., sex biases in nesting or marking behavior) can bias detection probability and consequently population monitoring. Whereas the impacts of in- 
dividual behavioral variability upon monitoring is well documented (Biro, 2013; Carter et al., 2012; Marescot et al., 2011), the impacts of inter-population behavioral variation on monitoring remains relatively ignored. In addition to variability in behavioral artefact construction, as remote monitoring methods become increasingly popular, variability in components such as camera trap shyness (e.g., Kalan et al. 2019) also impacts our ability to accurately estimate wildlife populations and to reliably compare estimates across species and populations. Group-level behavioral variation has recently gained a significant amount of attention, as it has been argued to be a necessary and valuable tool to guide conservation action, if applied effectively (Brakes et al., 2021; Brakes et al., 2019; Carvalho et al., in press). Here, we describe how group-level behavioral variation has important impacts upon conservation monitoring beyond inter-individual level variation. We further illustrate the impact of temporal variation in behavior on the accuracy of population estimation. In addition to using behavioral variability as a tool for conservation, we must also understand the impacts of this variation to our ability to evaluate conservation action and apply it effectively. To do so, further research characterizing behavioral variation of relevant monitoring behaviors across individuals, time periods, populations, and environments must be performed.

In sum, in addition to using animal behavioral diversity as a tool for conservation, here we present evidence that behavioral diversity also can considerably complicate conservation monitoring. Growing evidence indicates that presumably stable metrics used in population assessment must be given greater attention than previously afforded, and that ways to account for animal behavioral flexibility must be considered in a variety of conservation contexts. Given current widespread loss in wildlife populations (Ceballos et al., 2017), identifying how to best incorporate behavioral variation into population monitoring and conservation intervention is becoming not only pertinent but absolutely necessary.

\section{SUPPORTING INFORMATION}

Additional information is available online in the Supporting Information section at the end of the online article. The authors are solely responsible for the content and functionality of these materials. Queries (other than absence of the material) should be directed to the corresponding author.

Appendix S1. Histogram of published nest decay rates of chimpanzees and bonobos.

Appendix S2. Published estimates of nesting behavior and decay for chimpanzees and bonobos, with references.

Appendix S3. Table of the effect of rainfall, group, and sex on nest construction behavior at Kokolopori Bonobo Reserve.

Appendix S4. Video of a bonobo constructing a day nest at the Kokolopori Bonobo Reserve (video credits: Liran Samuni).

\section{Acknowledgements}

This work is dedicated to the late Dr. Deborah Moore, who is deeply missed at Kokolopori. We are grateful to the Ministry of Scientific Research and Technology (MSRT) and the ICCN of the Democratic Republic of the Congo, as well as to residents of the surrounding communities for facilitating our research and grant access to the Kokolopori Bonobo Reserve. We especially thank the team of local assistants for their invaluable contribution to data collection and bonobo tracking. Liran Samuni facilitated data collection in the field as well as kindly provided helpful feedback on earlier version of this manuscript. We sincerely thank Hjalmar Kühl for highlighting insightful avenues of improvement to the manuscript. This work was supported by Harvard University.

\section{Author contributions}

EW conceptualized, designed, and conducted the study; MS provided access to the data and assisted with conceptualization, and interpretation. Both authors contributed to the writing of the manuscript and have approved of the final submitted version.

\section{Statement on animal subjects}

This study complies with the ethical standards for animal research by the standards of the American Society of Primatology and the MSRT.

\section{LITERATURE CITED}

Altmann, J. (1974). Observational study of behavior: sampling methods. Behaviour, 49(3-4), 227-266.

Baayen, R. H. (2008). Analyzing Linguistic data: A Practical Introduction to Statistics Using R. In Cambridge University Press. Cambridge.

Barnes, R. F. (2001). How reliable are dung counts for estimating elephant numbers? African Journal of Ecology, 39(1), 1-9.

Bates, D., Mächler, M., Bolker, B., Walker, S. (2015). Fitting Linear Mixed-Effects Models Using lme4. Journal of Statistical Software, 67(i01).

Bessone, M., Booto, L., Santos, A. R., Kühl, H. S., Fruth, B. (2021). No time to rest: How the effects of climate change on nest decay threaten the conservation of apes in the wild. PLoS One, 16(6), e0252527.

Biro, P. A. (2013). Are most samples of animals systematically biased? Consistent individual trait differences bias samples despite random sampling. Oecologia, 171(2), 339-345.

Brakes, P., Carroll, E. L., Dall, S. R., Keith, S. A., McGregor, P. K., Mesnick, S. L., Noad, M. J., Rendell, L., Robbins, M. M., Rutz, C. (2021). A deepening understanding of animal culture suggests lessons for conservation. Proceedings of the Royal Society B, 288(1949), 20202718.

Brakes, P., Dall, S. R., Aplin, L. M., Bearhop, S., Carroll, E. L., Ciucci, P., Fishlock, V., Ford, J. K., Garland, E. C., Keith, S. A. (2019). Animal cultures matter for conservation. Science, 363(6431), 1032-1034. 
Buckland, S. T., Anderson, D. R., Burnham, K. P., Laake, J. L., Borchers, D. L., Thomas, L. (2001). Introduction to distance sampling: estimating abundance of biological populations. Oxford: Oxford University Press.

Buckland, S. T., Rexstad, E. A., Marques, T. A., Oedekoven, C. S. (2015). Distance sampling: methods and applications: Springer.

Campbell, G., Kuehl, H., Diarrassouba, A., N'Goran, P. K., Boesch, C. (2011). Long-term research sites as refugia for threatened and over-harvested species. Biology Letters, 7(5), 723-726.

Campos-Candela, A., Palmer, M., Balle, S., Alós, J. (2018). A camera-based method for estimating absolute density in animals displaying home range behaviour. Journal of Animal Ecology, 87(3), 825-837.

Cappelle, N., Després-Einspenner, M. L., Howe, E. J., Boesch, C., Kühl, H. S. (2019). Validating camera trap distance sampling for chimpanzees. American Journal of Primatology, 81(3), e22962.

Carter, A. J., Heinsohn, R., Goldizen, A. W., Biro, P. A. (2012). Boldness, trappability and sampling bias in wild lizards. Animal Behaviour, 83, $1051 \mathrm{e} 1058$.

Carvalho, S., Wessling, E., Abwe, E. E., Almeida-Warren, K., Arandjelovic, M., Boesch, C., Danquah, E., Diallo, M. S., Hobaiter, C., Hockings, K., Humle, T., Ashegbofe Ikemeh, R., Kalan, A.K., Luncz, L., Ohashi, G., Pascual-Garrido, A., Piel, A., Samuni, L., Soiret, S., Sanz, C. K. Koops. (in press). Using non-human culture in conservation requires careful and concerted action. Conservation Letters.

Ceballos, G., Ehrlich, P. R., Dirzo, R. (2017). Biological annihilation via the ongoing sixth mass extinction signaled by vertebrate population losses and declines. Proceedings of the National Academy of Sciences, 114(30), E6089-E6096.

Crunchant, A. S., Borchers, D., Kühl, H., Piel, A. (2020). Listening and watching: do camera traps or acoustic sensors more efficiently detect wild chimpanzees in an open habitat? Methods in Ecology and Evolution, 11(4), 542-552.

Dobson, A. J., Barnett, A. G. (2018). An introduction to generalized linear models. CRC press.

Fruth, B., Hickey, J., André, C., Furuichi, T., Hart, J., Hart, T., Kuehl, H., Maisels, F., Nackoney, J., Reinartz, G. (2016). Pan paniscus. IUCN Red List.

Fruth, B., Hohmann, G. (1993). Ecological and behavioral aspects of nest building in wild bonobos (Pan paniscus). Ethology, 94(2), 113-126.

Furuichi, T. (2009). Factors underlying party size differences between chimpanzees and bonobos: a review and hypotheses for future study. Primates, 50(3), 197-209.

Hammond, T. T., Curtis, M. J., Jacobs, L. E., Tobler, M. W., Swaisgood, R. R., Shier, D. M. (2021). Behavior and detection method influence detection probability of a translocated, endangered amphibian. Animal Conservation, 24(3), 401-411.

Hashimoto, C., Furuichi, T. (2002). Current situation of bonobos in the Luo reserve, Equateur, democratic republic of Congo. In All Apes Great and Small (pp. 8390): Springer.

Hedges, S., Tyson, M. J., Sitompul, A. F., Kinnaird, M. F., Gunaryadi, D. (2005). Distribution, status, and conservation needs of Asian elephants (Elephas maximus) in Lampung Province, Sumatra, Indonesia. Biological Conservation, 124(1), 35-48.

Hernandez-Aguilar, R. A., Reitan, T. (2020). Deciding where to sleep: spatial levels of nesting selection in chimpanzees (Pan troglodytes) living in savanna at Issa, Tanzania. International Journal of Primatology, 41(6), 870-900.

Hickey, J. R., Nackoney, J., Nibbelink, N. P., Blake, S., Bonyenge, A., Coxe, S., Dupain, J., Emetshu, M., Furuichi, T., Grossmann, F. (2013). Human proximity and habitat fragmentation are key drivers of the rangewide bonobo distribution. Biodiversity and Conservation, 22(13), 3085-3104.

Hohmann, G., Fruth, B. (2003). Culture in bonobos? Between-species and within-species variation in behavior. Current Anthropology, 44(4), 563-571.

Howe, E. J., Buckland, S. T., Després-Einspenner, M. L., Kühl, H. S. (2017). Distance sampling with camera traps. Methods in Ecology and Evolution, 8(11), 15581565.

Inogwabini, B.-I., Bewa, M., Longwango, M., Abokome, M., Vuvu, M. (2008). The bonobos of the Lake Tumba-Lake Maindombe hinterland: threats and opportunities for population conservation. In The Bonobos (pp. 273-290): Springer.

IUCN, ICCN. (2012). Bonobo (Pan paniscus): conservation strategy 2012-2022. IUCN/ICCN, Gland.

Kalan, A. K., Kulik, L., Arandjelovic, M., Boesch, C., Haas, F., Dieguez, P., Barratt, C. D., Abwe, E. E., Agbor, A., Angedakin, S., Aubert, F., Ayimisin, E. A., Bailey, E., Bessone, M., Brazzola, G., Buh, V. E., Chancellor, R., Cohen, H., Coupland, C., Curran, B., Danquah, E., Deschner, T., Dowd, D., Eno-Nku, M., Michael Fay, J., Goedmakers, A., Granjon, A.-C., Head, J., Hedwig, D., Hermans, V., Jeffery, K. J., Jones, S., Junker, J., Kadam, P., Kambi, M., Kienast, I., Kujirakwinja, D., Langergraber, K. E., Lapuente, J., Larson, B., Lee, K. C., Leinert, V., Llana, M., Marrocoli, S., Meier, A. C., Morgan, B., Morgan, D., Neil, E., Nicholl, S., Normand, E., Ormsby, L. J., Pacheco, L., Piel, A., Preece, J., Robbins, M. M., Rundus, A., Sanz, C., Sommer, V., Stewart, F., Tagg, N., Tennie, C., Vergnes, V., Welsh, A., Wessling, E. G., Willie, J., Wittig, R. M., Yuh, Y. G., Zuberbühler, K., Kühl, H. S. (2020). Environmental variability supports chimpanzee behavioural diversity. Nature Communications, 11(1), 1-10.

Kamgang, S. A., Carme, T. C., Bobo, K. S., Abwe, E. E., Gonder, M. K., Sinsin, B. (2020). Assessment of in situ nest decay rate for chimpanzees (Pan troglodytes ellioti Matschie, 1914) in Mbam-Djerem National Park, Cameroon: implications for long-term monitoring. Pri- 
mates, 61(2), 189-200.

Kelleher, S. R., Silla, A. J., Byrne, P. G. (2018). Animal personality and behavioral syndromes in amphibians: a review of the evidence, experimental approaches, and implications for conservation. Behavioral Ecology and Sociobiology, 72(5), 1-26.

Kouakou, C. Y., Boesch, C., Kuehl, H. (2009). Estimating chimpanzee population size with nest counts: validating methods in Taï National Park. American Journal of Primatology, 71(6), 447-457.

Kuehl, H. S., Todd, A., Boesch, C., Walsh, P. D. (2007). Manipulating decay time for efficient large-mammal density estimation: gorillas and dung height. Ecological Applications, 17(8), 2403-2414.

Kühl, H. (2008). Best practice guidelines for the surveys and monitoring of great ape populations: IUCN.

Laing, S., Buckland, S., Burn, R., Lambie, D., Amphlett, A. (2003). Dung and nest surveys: estimating decay rates. Journal of Applied Ecology, 40(6), 1102-1111.

Lucchesi, S., Cheng, L., Janmaat, K., Mundry, R., Pisor, A., Surbeck, M. (2020). Beyond the group: how food, mates, and group size influence intergroup encounters in wild bonobos. Behavioral Ecology, 31(2), 519-532.

Luncz, L. V., Mundry, R., Boesch, C. (2012). Evidence for cultural differences between neighboring chimpanzee communities. Current Biology, 22(10), 922-926.

Marescot, L., Pradel, R., Duchamp, C., Cubaynes, S., Marboutin, E., Choquet, R., Miquel, C., Gimenez, O. (2011). Capture-recapture population growth rate as a robust tool against detection heterogeneity for population management. Ecological Applications, 21(8), 2898-2907.

Merrick, M. J., Koprowski, J. L. (2017). Should we consider individual behavior differences in applied wildlife conservation studies? Biological Conservation, 209, 34-44.

Moeller, A. K., Lukacs, P. M., Horne, J. S. (2018). Three novel methods to estimate abundance of unmarked animals using remote cameras. Ecosphere, 9(8), e02331.

Mohneke, M., Fruth, B. (2008). Bonobo (Pan paniscus) density estimation in the SW-Salonga National Park, Democratic Republic of Congo: common methodology revisited. In The Bonobos (pp. 151-166): Springer.

Morgan, D., Sanz, C., Onononga, J. R., Strindberg, S. (2006). Ape abundance and habitat use in the Goualougo Triangle, Republic of Congo. International Journal of Primatology, 27(1), 147-179.

Morgan, D., Sanz, C., Onononga, J. R., Strindberg, S. (2016). Factors influencing the survival of sympatric gorilla (Gorilla gorilla gorilla) and chimpanzee (Pan troglodytes troglodytes) nests. International Journal of Primatology, 37(6), 718-737.

Nackoney, J., Williams, D. (2013). A comparison of scenarios for rural development planning and conservation in the Democratic Republic of the Congo. Biological Conservation, 164, 140-149.

Nakashima, Y., Fukasawa, K., Samejima, H. (2018). Estimating animal density without individual recognition using information derivable exclusively from camera traps. Journal of Applied Ecology, 55(2), 735-744.

Nchanji, A. C., Plumptre, A. J. (2001). Seasonality in elephant dung decay and implications for censusing and population monitoring in south-western Cameroon. African Journal of Ecology, 39(1), 24-32.

Oberosler, V., Groff, C., Iemma, A., Pedrini, P., Rovero, F. (2017). The influence of human disturbance on occupancy and activity patterns of mammals in the Italian Alps from systematic camera trapping. Mammalian Biology, 87(1), 50-61.

Osipova, L., Okello, M., Njumbi, S., Ngene, S., Western, D., Hayward, M., Balkenhol, N. (2019). Using stepselection functions to model landscape connectivity for African elephants: accounting for variability across individuals and seasons. Animal Conservation, 22(1), 3548.

Plumptre, A. J. (2000). Monitoring mammal populations with line transect techniques in African forests. Journal of Applied Ecology, 37(2), 356-368.

Plumptre, A. J., Cox, D. (2006). Counting primates for conservation: primate surveys in Uganda. Primates, 47(1), 65-73.

Plumptre, A. J., Reynolds, V. (1997). Nesting behavior of chimpanzees: implications for censuses. International Journal of Primatology, 18(4), 475-485.

Pruetz, J. D., Bertolani, P. (2009). Chimpanzee (Pan troglodytes verus) behavioral responses to stresses associated with living in a savanna-mosaic environment: implications for hominin adaptations to open habitats. PaleoAnthropology, 252.

Reinartz, G. E., Isia, I. B., Ngamankosi, M., Wema, L. W. (2006). Effects of forest type and human presence on bonobo (Pan paniscus) density in the Salonga National Park. International Journal of Primatology, 27(2), 603634.

Rosenblatt, A. E., Heithaus, M. R., Mazzotti, F. J., Cherkiss, M., Jeffery, B. M. (2013). Intra-population variation in activity ranges, diel patterns, movement rates, and habitat use of American alligators in a subtropical estuary. Estuarine, Coastal and Shelf Science, 135, 182-190.

Rowcliffe, J. M., Kays, R., Kranstauber, B., Carbone, C., Jansen, P. A. (2014). Quantifying levels of animal activity using camera trap data. Methods in Ecology and Evolution, 5(11), 1170-1179.

Samuni, L., Wegdell, F., Surbeck, M. (2020). Behavioural diversity of bonobo prey preference as a potential cultural trait. eLife, 9, e59191.

Serckx, A., Huynen, M.-C., Bastin, J.-F., Hambuckers, A., Beudels-Jamar, R. C., Vimond, M., Raynaud, E., Kühl, H. S. (2014). Nest grouping patterns of bonobos (Pan paniscus) in relation to fruit availability in a forestsavannah mosaic. PLoS One, 9(4), e93742.

Stewart, F. A., Piel, A. K., Azkarate, J. C., Pruetz, J. D. (2018). Savanna chimpanzees adjust sleeping nest architecture in response to local weather conditions. American Journal of Physical Anthropology, 166(3), 
549-562.

Stolwijk, A., Straatman, H., Zielhuis, G. (1999). Studying seasonality by using sine and cosine functions in regression analysis. Journal of Epidemiology Community Health, 53(4), 235-238.

Strindberg, S., Maisels, F., Williamson, E. A., Blake, S., Stokes, E. J., Aba'a, R., Abitsi, G., Agbor, A., Ambahe, R. D., Bakabana, P. C. (2018). Guns, germs, and trees determine density and distribution of gorillas and chimpanzees in Western Equatorial Africa. Science Advances, 4(4), eaar2964.

Surbeck, M., Coxe, S., Lokasola, A. L. (2017). Lonoa: The Establishment of a Permanent Field Site for Behavioural Research on Bonobos in the Kokolopori Bonobo Reserve. Pan Africa News, 24(2), 13-15.

Todd, A. F., Kuehl, H. S., Cipolletta, C., Walsh, P. D. (2008). Using dung to estimate gorilla density: modeling dung production rate. International Journal of Primatology, 29(2), 549-563.

Van Krunkelsven, E. (2001). Density estimation of bonobos (Pan paniscus) in Salonga National Park, Congo. Biological Conservation, 99(3), 387-391.

Viquerat, S. M. A., Muller, M., Kiffner, C., Waltert, M., Bobo, K. S. (2012). Estimating forest duiker (Cephalophinae) density in Korup National Park: a case study on the performance of three line transect methods. South African Journal of Wildife Research, 42(1), 1-10.

Walsh, P. D., White, L. J. (2005). Evaluating the steady state assumption: simulations of gorilla nest decay. Ecological Applications, 15(4), 1342-1350. 
Failure to account for behavioral variability overestimates bonobo populations and compromises accuracy in population monitoring

\section{SUPPLEMENTARY MATERIAL}

APPENDIX S1:

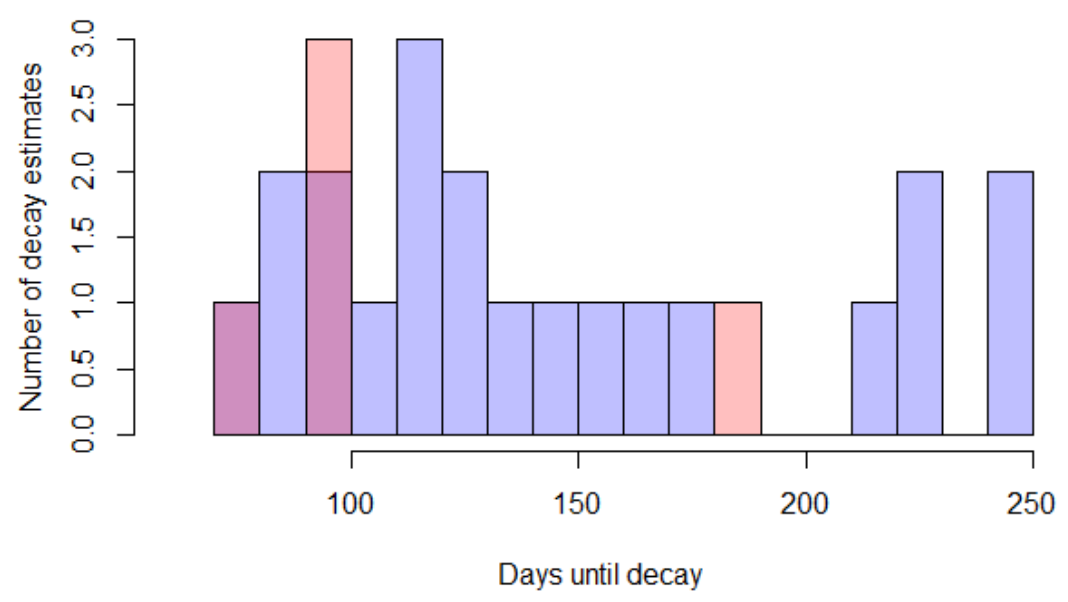

Figure S1. Summary of published nest decay rates of chimpanzees (blue) and bonobos (pink). 


\section{APPENDIX S2}

Published estimates of nesting behavior and decay for chimpanzees and bonobos, with references.

Table S1. Published (a) nest decay rates and (b) construction rates for chimpanzees and bonobos.

\begin{tabular}{|c|c|c|c|}
\hline \multicolumn{4}{|c|}{ (a) Nest decay rates } \\
\hline Species & Days & Location & Reference \\
\hline Bonobo & 76 & LuiKotale, DRC & Mohneke \& Fruth 2008 \\
\hline Bonobo & 96 & LuiKotale, DRC & Bessone et al. 2021 \\
\hline Bonobo & 99 & Lomako, DRC & van Krunkelsven 2001 \\
\hline Bonobo & 99 & Lomako, DRC & Eriksson 1999 \\
\hline Bonobo & 183 & Malebo, DRC & Serckx et al. 2014 \\
\hline Chimpanzee & 73 & Taï, Côte d'Ivoire & Marchesi et al. 1995 \\
\hline Chimpanzee & 95 & Taï, Côte d'Ivoire & Kouakou et al. 2009 \\
\hline Chimpanzee & 161 & Taï, Côte d'Ivoire & $\begin{array}{l}\text { Wild Chimpanzee Foundation; via } \\
\text { Heinicke et al. } 2019\end{array}$ \\
\hline Chimpanzee & 85 & Djoroutou, Côte d'Ivoire & $\begin{array}{l}\text { Wild Chimpanzee Foundation; via } \\
\text { Heinicke et al. } 2019\end{array}$ \\
\hline Chimpanzee & 179 & Comoé, Côte d'Ivoire & Laupuente et al. 2020 \\
\hline Chimpanzee & 106 & Lope, Gabon & Hall et al. 1998 \\
\hline Chimpanzee & 114 & Belinga, Gabon & Tutin \& Fernandez 1984 \\
\hline Chimpanzee & 146 & $\begin{array}{l}\text { (Goualougo) Nouabalé-Ndoki } \\
\text { National Park, Republic of Congo }\end{array}$ & Morgan et al. 2016 \\
\hline Chimpanzee & 90 & $\begin{array}{l}\text { (Goualougo) Nouabalé-Ndoki } \\
\text { National Park, Republic of Congo }\end{array}$ & Morgan et al. 2006 \\
\hline Chimpanzee & 111 & Kibale, Uganda & Ghigleri 1979; Ghigleri 1984 \\
\hline Chimpanzee & 243 & Dindefelo, Senegal & Heinicke et al. 2019 \\
\hline Chimpanzee & $243 / 432^{*}$ & Issa, Tanzania & Stewart et al. 2011 \\
\hline Chimpanzee & 218 & Fouta Djallon, Guinea & $\begin{array}{l}\text { Wild Chimpanzee Foundation; via } \\
\text { Heinicke et al. } 2019\end{array}$ \\
\hline Chimpanzee & 221 & Fouta Djallon, Guinea & Ham 1998 \\
\hline Chimpanzee & 229 & Haut Niger, Guinea & Fleury-Brugiere \& Brugiere 2010 \\
\hline Chimpanzee & 154 & Sapo, Liberia & $\begin{array}{l}\text { PanAfrican Programme; via } \\
\text { Heinicke et al. } 2019\end{array}$ \\
\hline Chimpanzee & 146 & Sapo, Liberia (marshes) & $\begin{array}{l}\text { PanAfrican Programme; via } \\
\text { Heinicke et al. } 2019\end{array}$ \\
\hline Chimpanzee & 135 & TRIDOM Landscape, Cameroon & Nzooh Dongmo et al. 2016 \\
\hline Chimpanzee & 127 & Mbam-Djerem, Cameroon & Kamgang et al. 2020 \\
\hline Chimpanzee & 97 & Dja, Cameroon & Bruce et al. 2018 \\
\hline Chimpanzee & 130 & Campo Ma'an, Cameroon & Matthews \& Matthews 2004 \\
\hline Chimpanzee & 133 & Campo Ma'an, Cameroon & Nzooh Dongmo et al. 2015 \\
\hline \multicolumn{4}{|c|}{ (b) Nest construction rates } \\
\hline Species & nests/day & Location & Reference \\
\hline Bonobo & 1.92 & Kokolopori, DRC & This study \\
\hline Bonobo & 1.37 & Lomako, DRC & Mohneke \& Fruth 2008 \\
\hline Chimpanzee & 1.09 & Budongo, Uganda & Plumptre \& Reynolds 1997 \\
\hline
\end{tabular}




\begin{tabular}{|l|l|l|l|} 
Chimpanzee & 1.09 & Goualougo, Rep Congo & Morgan et al. 2006 \\
\hline Chimpanzee & 1.14 & Taï, Côte d'Ivoire & Kouakou et al. 2009 \\
\hline
\end{tabular}

${ }^{*}$ Differentiated between vegetation coverage types, no site average provided

\section{LITERATURE CITED}

Bessone, M., Booto, L., Santos, A. R., Kühl, H. S., \& Fruth, B. (2021). No time to rest: How the effects of climate change on nest decay threaten the conservation of apes in the wild. PLoS One, 16(6), e0252527.

Bruce, T., Ndjassi, C., Fowler, A., Ndimbe, M., Fankem, O., Mbodbda, R. B. T., Kobla, A.-S., Puemo, F. A. W., Lushimba, A., Amin, R., Wacher, T., Grange-Chamfray, S., \& Olson, D. (2018). Faunal Inventory of the Dja Faunal Reserve, Cameroon - 2018. Ministry of Forests and Wildlife (MINFOF), Zoological Society of London - Cameroon Country Programme, African Wildlife Foundation, Yaoundé, Cameroon.

Eriksson, J. (1999). A survey of the forest and census of the bonobo (Pan paniscus) population between the Lomako and Yekokora Rivers in the Equateur Province, DR Congo. MS thesis, Univ. of Uppsala.

Fleury-Brugiere, M.-C., \& Brugiere, D. (2010). High population density of Pan troglodytes verus in the Haut Niger National Park, Republic of Guinea: implications for local and regional conservation. International Journal of Primatology, 31(3), 383-392.

Ghiglieri, M. P. (1984). 6. Feeding Ecology and Sociality of Chimpanzees in Kibale Forest, Uganda. In Adaptations for foraging in nonhuman primates (pp. 161-194): Columbia University Press.

Hall, J. S., White, L. J., Inogwabini, B.-I., Omari, I., Morland, H. S., Williamson, E. A., Saltonstall, K., Walsh, P., Sikubwabo, C., \& Bonny, D. (1998). Survey of Grauer's gorillas (Gorilla gorilla graueri) and eastern chimpanzees (Pan troglodytes schweinfurthi) in the Kahuzi-Biega National Park lowland sector and adjacent forest in eastern Democratic Republic of Congo. International Journal of Primatology, 19(2), 207-235.

Ham, R. (1998). Chimpanzee survey in the Republic of Guinea. Report for the European Union.

Heinicke, S., Mundry, R., Boesch, C., Amarasekaran, B., Barrie, A., Brncic, T., Brugière, D., Campbell, G., Carvalho, J., \& Danquah, E. (2019). Characteristics of positive deviants in western chimpanzee populations. Frontiers in Ecology and Evolution, 7, 16.

Kamgang, S. A., Carme, T. C., Bobo, K. S., Abwe, E. E., Gonder, M. K., \& Sinsin, B. (2020). Assessment of in situ nest decay rate for chimpanzees (Pan troglodytes ellioti Matschie, 1914) in MbamDjerem National Park, Cameroon: implications for long-term monitoring. Primates, 61(2), 189200.

Kouakou, C. Y., Boesch, C., \& Kuehl, H. (2009). Estimating chimpanzee population size with nest counts: validating methods in Taï National Park. American Journal of Primatology: Official Journal of the American Society of Primatologists, 71(6), 447-457.

Lapuente, J., Ouattara, A., Köster, P. C., \& Linsenmair, K. E. (2020). Status and distribution of Comoé Chimpanzees: combined use of transects and camera traps to quantify a low-density population in savanna-forest mosaic. Primates, 61(5), 647-659.

Marchesi, P., Marchesi, N., Fruth, B., \& Boesch, C. (1995). Census and distribution of chimpanzees in Cote d'Ivoire. Primates, 36(4), 591-607.

Matthews, A., \& Matthews, A. (2004). Survey of gorillas (Gorilla gorilla gorilla) and chimpanzees (Pan troglodytes troglodytes) in Southwestern Cameroon. Primates, 45(1), 15-24.

Morgan, D., Sanz, C., Onononga, J. R., \& Strindberg, S. (2006). Ape abundance and habitat use in the Goualougo Triangle, Republic of Congo. International Journal of Primatology, 27(1), 147-179.

Morgan, D., Sanz, C., Onononga, J. R., \& Strindberg, S. (2016). Factors influencing the survival of sympatric gorilla (Gorilla gorilla gorilla) and chimpanzee (Pan troglodytes troglodytes) nests. International Journal of Primatology, 37(6), 718-737.

Nzooh Dongmo, Z.L., N'Goran, P. K., Fondja, C., \& Nkono, J. (2015). Evaluation de la Dynamique des Populations de Grands et Moyens Mammiferes dans le Domaine Dorestier Permanent de l'Unite Technique Operationnelle Campo Ma'an. Service de Conservation du Parc National de Campo Ma'an, WWF Regional Office for Africa. Yaounde, Cameroon.

Nzooh Dongmo, Z. L., N'goran, K. P., Etoga, G., Belinga, J. P., Fouda, E., Bandjouma, M., \& Dongmo, P. (2016). Les populations de grands et moyens mammifères dans le segment Cameroun du 
Paysage TRIDOM: Forêt de Ngoyla-Mintom, PN Boumba Bek et PN Nki et leurs zones périphériques. Rapport Technique. Yaoundé, Cameroun.

Plumptre, A. J., \& Reynolds, V. (1997). Nesting behavior of chimpanzees: implications for censuses. International Journal of Primatology, 18(4), 475-485.

Serckx, A., Huynen, M.-C., Bastin, J.-F., Hambuckers, A., Beudels-Jamar, R. C., Vimond, M., Raynaud, E., \& Kühl, H. S. (2014). Nest grouping patterns of bonobos (Pan paniscus) in relation to fruit availability in a forest-savannah mosaic. PLoS One, 9(4), e93742.

Stewart, F. A., Piel, A. K., \& McGrew, W. C. (2011). Living archaeology: artefacts of specific nest site fidelity in wild chimpanzees. Journal of Human Evolution, 61(4), 388-395.

Tutin, C. E., \& Fernandez, M. (1984). Nationwide census of gorilla (Gorilla g. gorilla) and chimpanzee (Pan t. troglodytes) populations in Gabon. American Journal of Primatology, 6(4), 313-336.

Van Krunkelsven, E. (2001). Density estimation of bonobos (Pan paniscus) in Salonga National Park, Congo. Biological Conservation, 99(3), 387-391.

\section{APPENDIX S3:}

Table S2. Effect of rainfall, group, and sex on nest construction behavior at Kokolopori Bonobo Reserve $(n=210)$. Statistically significant results $(p \leq 0.05)$ appear in bold italics.

\begin{tabular}{|c|c|c|c|}
\hline Predictor & Estimate \pm SE & $x^{2}$ & p-value \\
\hline Intercept & $-1.833 \pm 0.118$ & - & - \\
\hline Rainfall & $0.002 \pm 0.001$ & 5.179 & 0.023 \\
\hline Group (Fekako) $)^{1}$ & $0.061 \pm 0.115$ & 0211 & 0012 \\
\hline Group (Kokoalongo) ${ }^{1}$ & $0.041 \pm 0.094$ & 0.341 & 0.843 \\
\hline Sex $(\text { Male })^{2}$ & $-0.111 \pm 0.094$ & 1.404 & 0.236 \\
\hline
\end{tabular}

${ }^{1}$ Reference category: Ekalakala; ${ }^{2}$ Reference category: Female 